\title{
Evaluation of the functionality and mobility of community-dwelling older adults in primary health care
}

Abstract

Objective: To evaluate the functional capacity and mobility of older adults treated in primary health care and the association between adverse outcomes (functional dependence and reduced mobility) and sociodemographic and health conditions. Method: A cross-sectional and analytical epidemiological study was carried out in the municipal region of Caicó, Rio Grande do Norte, Brazil. Sociodemographic variables, presence of comorbidities, practice of physical activity, functional capacity (Lawton Scale) and mobility (Timed Up and Go Test) were investigated. Data analysis was performed using descriptive statistics, followed by bivariate analysis to investigate association variables and multivariate analysis (logistic regression). Results: Among the 109 elderly people evaluated, 29.4\% were dependent in instrumental activities of daily living (IADL) and 67.9\% had reduced mobility. The present study found a significant association between dependence in IADL and age equal to or greater than 75 years; while not practicing physical activity remained a factor of association with reduced mobility, regardless of sex, age and presence of co-morbidities. Conclusion: The findings emphasize the importance of the practice of physical activity, which was associated with better mobility, the construction of spaces of health promotion and disease prevention to encourage active aging for older adults, as well as a multi and interprofessional approach to comprehensive health care for older adults, with the use of functionality assessment tools.

\footnotetext{
Universidade Federal Rio Grande Norte, Escola Multicampi de Ciências Médicas, Programa de Residência Multiprofissional em Atenção Básica. Caicó, RN, Brasil.

2 Universidade Federal Rio Grande Norte, Escola Multicampi de Ciências Médicas. Caicó, RN, Brasil.
}

Research Funding: Coordenação de Aperfeiçoamento de Pessoal de Nível Superior - Brasil (CAPES) - Código de Financiamento 001.

The authors declare there are no conflicts of interest involved in this study
Keywords: Aging. Primary Health Care. Mobility Limitation. Activities of Daily Living. Functionality. Disability. 


\section{INTRODUCTION}

Population aging in Brazil is accelerating, resulting in repercussions for the public health system, with the increased prevalence of chronic non-communicable and/or disabling diseases ${ }^{1}$. This scenario challenges professionals and researchers to optimize care services to provide comprehensive and resolutive care for the growing older population ${ }^{2}$.

The National Health Policy for Older Adults (or PNSPI) describes older adults as a group of greater vulnerability and therefore suggests the incorporation, in primary care, of tools that improve the quality and resolutive capacity of care. To this end, the policy advocates a multidimensional approach to older adults, encouraging the use of technical instruments for functional and psychosocial assessment, which enable the early detection of risk factors for adverse events, as well as the implementation of preventive and curative actions in a timely manner ${ }^{3}$.

In older populations, functional capacity is an important evaluation and intervention parameter in the quest for active aging ${ }^{4,5}$. This is because functional disability of a physical and/or mental nature has great impacts on the life of older adults in terms of increased morbidity and mortality and the risk of hospitalization and permanence in long-term care facilities, resulting in social and economic burden for the older adults themselves, their families and the health system ${ }^{6}$. In this sense, the decline of mobility in older adults is an important predictor of health in old age, allowing the early detection of sarcopenia and functional limitations, and operationalizing the health care of older adults to prevent adverse events, such as functional disability and falls ${ }^{7}$.

In Brazil, primary care should function as an organizer of care in the public health system, with a fundamental role in the comprehensive care of older adults $^{8}$. In this scenario, comprehensive geriatric assessment (CGA) represents an instrument for the multidimensional diagnosis of older adults, contributing to the improvement and maintenance of functional capacity and mobility ${ }^{9}$ However, it is necessary to establish strategies to encourage the greater implementation of and adherence to this instrument in primary care.
The importance of the present study is based on aspects related to health planning in accordance with the current reality, health surveillance and comprehensive care of older adults, and it is committed to encouraging the use of validated and reliable instruments for the evaluation of such individuals by members of primary health care teams.

The objective of the present study was therefore to evaluate the functional capacity and mobility of older adults treated by primary health care, and the association between adverse outcomes (functional dependence and reduced mobility) and sociodemographic aspects and health conditions.

\section{METHOD}

A cross-sectional and analytical epidemiological study was conducted from September to November 2018.

The present study was carried out in Caicó, a municipal district in the state of Rio Grande do Norte (RN), Brazil, $282 \mathrm{~km}$ from the state capital, Natal. According to 2010 census data, Caicó has an HDI of 0.71 , the fourth best in the state. In addition, it has an increasing human longevity levels, with a life expectancy of around 74.4 years, higher than the Brazilian average and one of the highest in municipal districts in the north and north east of Brazil. Caicó has 5,980 people aged 65 and over, considering both the urban and rural population ${ }^{10}$. In all, it has 18 basic health units (BHU) with a population coverage of around $95 \%$.

The sample of the present study was obtained by convenience, based on the work of the students of the Multiprofessional Residency Program in Primary Care of the Multicampi School of Medical Sciences of Rio Grande do Norte (UFRN). A convenience sample was chosen as the BHU registration records were not up to date and did not distinguish between the rural and urban population, nor between institutionalized older adults and those living in the community.

Thus, older adults aged 65 years and above, of both sexes and treated at five BHU were included. Exclusion criteria were: not being located for evaluation after 
three attempts during recruitment and being unable to complete all stages of data collection.

The information collected was related to sociodemographic characteristics, the presence of comorbidities, physical activity, functional capacity and mobility. The data were collected by a team of three basic care (BC) residents, who were duly trained to apply the collection instruments. The participants were invited to participate in the research and sign a Informed Consent.

The following information was collected: sex, age, marital status, color/ethnicity, education and family income. The presence of comorbidities was based on self-reported information, considering the medical diagnosis in the last year of the following most frequent chronic diseases among older adults. ${ }^{11}$ : heart diseases; arterial hypertension; diabetes mellitus; malignant tumors; arthritis or rheumatism; lung diseases; depression; osteoporosis and strokes. Presence of comorbidities was considered the selfreporting of two or more diseases.

The practice of physical activity was investigated by asking the participants if they practiced or had practiced any kind of physical exercise and/or sport in the previous three months, and how often.

Data on functional capacity were obtained using the Lawton Scale, a validated instrument to assess instrumental activities of daily living (IADL). In this scale, the questions investigate the ability of the individual to perform tasks such as preparing meals and performing housework, asking whether or not they perform such tasks and whether or not they do so with the help of others. The maximum score is 27 points and the minimum nine points. Independence in performing such activities is directly related to the capability to live independently in the community ${ }^{12}$.

Mobility was evaluated using the Timed Up and Go (TUG) test. This test is used to assess the functional mobility of the individual through the analysis of sitting balance, seated to standing transfers, gait stability and change in gait direction, without the use of compensatory strategies ${ }^{13,14}$. Older adults who completed the TUG within 10 seconds were considered to have good mobility; those who completed the TUG within 11 seconds or more were considered to have reduced mobility, following the Edmonton Frail Scale (EFS) classification for risk of frailty. ${ }^{15}$.

Data were stored and processed. Descriptive statistics (frequency, measures of central tendency and dispersion) were used to characterize the sample, followed by bivariate analysis $\left(\mathrm{X}^{2}\right)$ to investigate the variables of association, while multivariate analysis (logistic regression) was used to adjust for possible confounding variables. A 95\% CI and significance level of $\alpha=5 \%$ were adopted.

The present study was approved by the Research Ethics Committee of the Trairi Faculty of Health Sciences (or FACISA) of the Universidade Federal do Rio Grande do Norte (protocol No. 2.452.346), as determined by National Health Council Resolution No. 466/2012, which defines the guidelines and regulatory standards governing research involving human beings.

\section{RESULTS}

A total of 113 older adults were interviewed, of whom four were excluded because they did not complete all the steps of the study. Thus, 109 older adults were included in the data analysis, with a mean age of $71.5( \pm 5.51)$ years (minimum age 65 and maximum 88).

Table 1 characterizes the sample according to sociodemographic variables and health conditions. Most were female (77.1\%); aged 65 to 69 years $(45.9 \%)$; married (47.7\%); white $(46.8 \%)$ or brownskinned (33.0\%); with an educational level below primary school $(73.4 \%)$ and an income lower than twice the minimum wage $(51.4 \%)$. In terms of clinical conditions, $57.8 \%$ said they had two or more comorbidities and only $39.4 \%$ said they performed some type of physical activity. 
Table 1. Distribution of sociodemographic characteristics and health conditions of older adults (N=109). Caicó, RN, 2019.

\begin{tabular}{|c|c|}
\hline Sociodemographic variables & $\mathrm{n}(\%)$ \\
\hline \multicolumn{2}{|l|}{ Sex } \\
\hline Female & $84(77.1)$ \\
\hline Male & $25(22.9)$ \\
\hline \multicolumn{2}{|l|}{ Age range (years) } \\
\hline 65 to 69 & $50(45.9)$ \\
\hline 70 to 74 & $27(24.8)$ \\
\hline 75 or more & $32(29.4)$ \\
\hline \multicolumn{2}{|l|}{ Marital status } \\
\hline Single & $12(11.0)$ \\
\hline Married & $52(47.7)$ \\
\hline Divorced/Separated & $12(11.0)$ \\
\hline Widowed & $33(30.3)$ \\
\hline \multicolumn{2}{|l|}{ Ethnicity } \\
\hline "Yellow" (Asian-Brazilian) & $6(5.5)$ \\
\hline White & $51(46.8)$ \\
\hline Indigenous & $1(0.9)$ \\
\hline Black & $15(13.8)$ \\
\hline "Brown" (Mixed-race) & $36(33.0)$ \\
\hline \multicolumn{2}{|l|}{ Schooling } \\
\hline Illiterate & $10(9.2)$ \\
\hline Incomplete primary & $70(64.2)$ \\
\hline Complete primary & $22(20.2)$ \\
\hline Complete secondary & $6(5.5)$ \\
\hline Higher & $1(0.9)$ \\
\hline \multicolumn{2}{|l|}{ Income (minimum wage) } \\
\hline Less than minimum wage & $10(9.2)$ \\
\hline Min. wage to twice min. wage & $46(42.2)$ \\
\hline Twice minimum wage or more & $53(48.6)$ \\
\hline \multicolumn{2}{|l|}{ Clinical variables } \\
\hline \multicolumn{2}{|l|}{ Presence of comorbidities } \\
\hline Yes & $63(57.8)$ \\
\hline No & $46(42.2)$ \\
\hline \multicolumn{2}{|l|}{ Practice physical activity } \\
\hline Yes & $43(39.4)$ \\
\hline No & $66(60.6)$ \\
\hline \multicolumn{2}{|l|}{ Frequency of physical activity } \\
\hline None & $66(60.6)$ \\
\hline 1 to 2 days per week & $14(12.8)$ \\
\hline 3 to 4 days per week & $7(64.4)$ \\
\hline 5 to 6 days per week & $18(16.5)$ \\
\hline Every day & $4(3.7)$ \\
\hline
\end{tabular}


Table 2 presents the result of the bivariate analysis of the association between functional capacity and sociodemographic variables and health conditions. Among the 109 older adults evaluated, 29.4\% ( $n=32)$ were dependent in the performance of IADL. The chi-squared test showed a significant association between dependence in the performance of IADL and the age group 75 years or older $(p<0.001)$.
A total of $67.9 \%(n=73)$ of the sample had reduced mobility in the TUG test. Table 3 describes the association between TUG and the sociodemographic variables and health conditions, with a significant association observed between reduced mobility and the presence of comorbidities $(p=0.04)$ and nonphysical activity $(p<0.01)$.

Table 2. Bivariate analysis of the relationship between functional capacity and sociodemographic variables and health conditions ( $\mathrm{N}=109)$. Caicó, $\mathrm{RN}, 2019$.

\begin{tabular}{llll}
\hline Variables & Functional Capacity & & $p$-value \\
\hline & $\begin{array}{l}\text { Dependent - IADL } \\
\mathrm{n}(\%)\end{array}$ & $\begin{array}{l}\text { Independent - IADL } \\
\mathrm{n}(\%)\end{array}$ & 0.40 \\
\hline Gender & $9(36.0)$ & $16(64.0)$ & $61(72.6)$ \\
Male & $23(27.4)$ & & $<0.001$ \\
Feminine & $13(16.9)$ & $64(83.1)$ & 0.13 \\
Age range (years) & $19(59.4)$ & $13(40.6)$ & \\
65 to 74 & & $41(65.1)$ & 0.30 \\
75 or more & $22(34.9)$ & $36(78.3)$ & \\
\hline Presence of comorbidities & $10(21.7)$ & $28(65.1)$ & $49(64.2)$ \\
Yes & $15(34.9)$ & & \\
Not & $17(25.8)$ & & \\
Practice of physical activity & & & \\
Yes & &
\end{tabular}

$\mathrm{IADL}=$ instrumental activities of daily living.

Table 3. Bivariate analysis of Timed Up and Go (TUG) mobility with sociodemographic variables and health conditions (N=109). Caicó, RN, 2019.

\begin{tabular}{llll}
\hline Variables & TUG Mobility & p-valuer \\
\hline & $\begin{array}{l}\text { Good Mobility } \\
(\mathrm{TUG} \leq 10 \mathrm{~s})\end{array}$ & $\begin{array}{l}\text { Reduced Mobility } \\
(\mathrm{TUG} \geq 11 \mathrm{~s})\end{array}$ & \\
$\mathrm{n}(\%)$ & $\mathrm{n}(\%)$ & 0.81 \\
\hline Sex & $9(36.0)$ & $16(64.0)$ & \\
Male & $27(32.1)$ & $57(67.9)$ & 0.12 \\
Feminine & & & \\
\hline Age range (years) & $29(37.7)$ & $48(62.3)$ & \\
65 to 74 & $7(21.9)$ & $25(78.1)$ & 0.04 \\
75 or more & & $47(74.6)$ & \\
\hline Presence of comorbidities & $16(25.4)$ & $26(56.5)$ & $<0.01$ \\
Yes & $20(43.5)$ & $22(51.2)$ & \\
Not & & $51(77.3)$ & \\
\hline Practice of physical activity & $21(48.8)$ & & \\
Yes & $15(22.7)$ & & \\
Not & & & \\
\hline
\end{tabular}


Following bivariate analysis, binary logistic regression analysis was performed to control for possible confounding variables, and to evaluate factors associated with the functional capacity and mobility of community-dwelling older adults (Tables 4 and 5). Thus, advanced age was confirmed as a factor of association for dependence in the performance of IADL, and the non-practicing of physical activity remained as a factor of association for reduced mobility, regardless of gender, age and the presence of comorbidities.

Table 4. Binary logistic regression model to assess factors associated with functional capacity (IADL) among community-dwelling older adults. Caicó, RN, 2019.

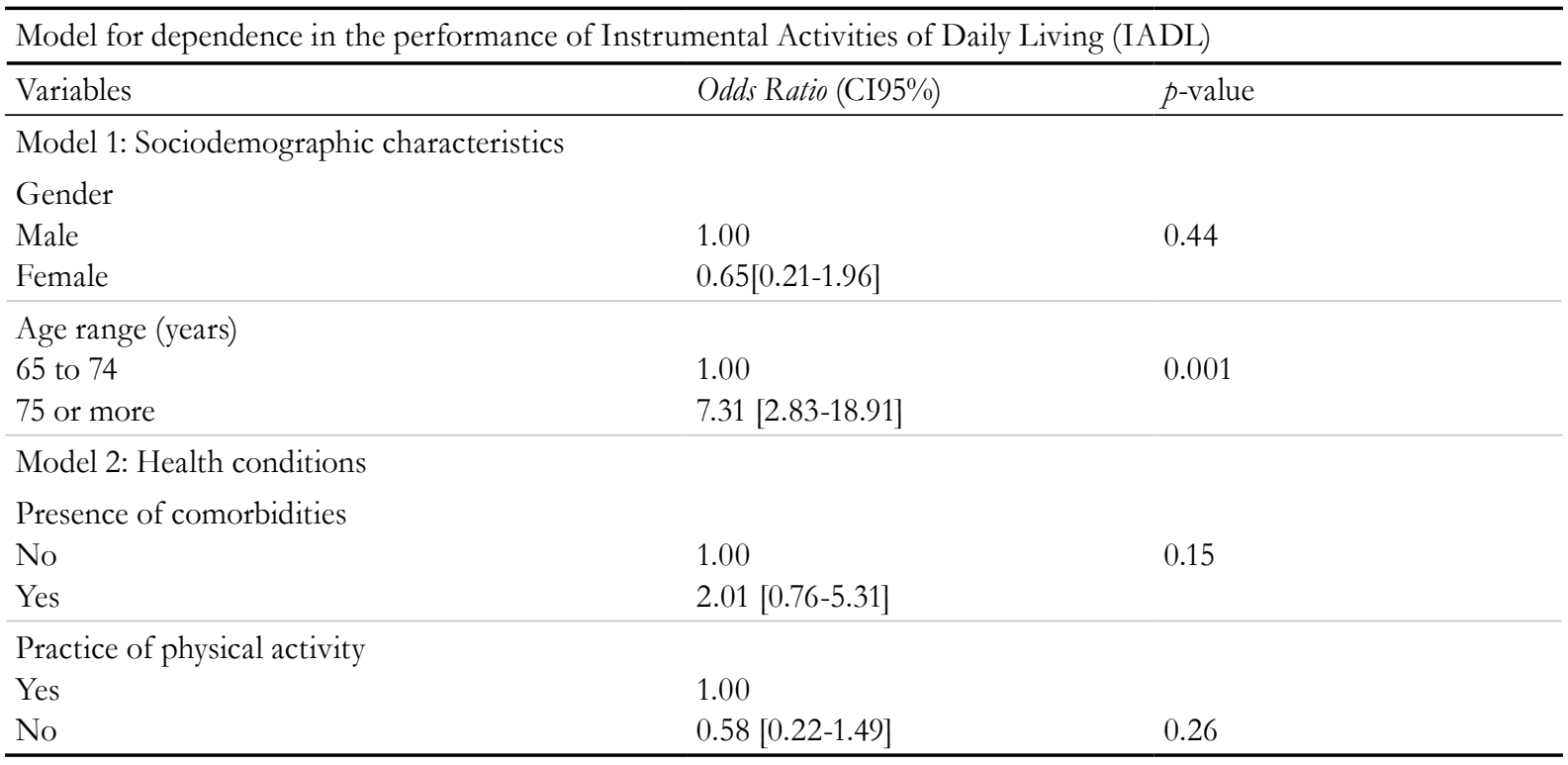

Table 5. Binary logistic regression model for assessing factors associated with the mobility (TUG) of communitydwelling older adults. Caicó, RN, 2019.

\begin{tabular}{lll}
\hline Model for reduced mobility (TUG $\geq 11 \mathrm{~s})$ & & \\
\hline Variables & Odds Ratio (IC 95\%) & \\
\hline $\begin{array}{l}\text { Model 1: Sociodemographic characteristics } \\
\text { Sex }\end{array}$ & 1.00 & 0.78 \\
Male & $1.14[0.41-3.16]$ & \\
Female & 1.00 & 0.10 \\
\hline Age range (years) & $2.33[0.84-6.45]$ & \\
65 to 74 & & \\
75 or more & 1.00 & 0.06 \\
\hline Model 2: Health conditions & $2.26[0.95-5.37]$ & \\
Presence of comorbidities & & 0.005 \\
No & 1.00 & \\
Yes & $3.49[1.46-8.31]$ & \\
\hline Practice of physical activity & & \\
Yes & & \\
No &
\end{tabular}




\section{DISCUSSION}

The profile of the sample of the present study was consistent with other studies in Brazil, with a predominance of women $(77.1 \%)^{1,16}$. Gerontology researchers characterize this process as the feminization of old age, and as a phenomenon that especially occurs at the most advanced ages ${ }^{17}$.

In terms of age group, the predominant age of older adults in the present study was 65 to 69 years. There was a significant association between dependence in IADL and age $(p<0,001)$, a finding that reaffirms the fact that advancing age may be related to a higher degree of dependence among older adults, corroborating other studies ${ }^{18,19}$. It is known that advanced age generates greater impairment of physical and functional aspects ${ }^{20}$. Moreover, in people over 75 , there is a higher risk of developing chronic and degenerative diseases, reducing the ability of older adults to live independently and enjoy active aging. ${ }^{21}$

No significant associations were observed in the present study between functional capacity and gender, the presence of comorbidities and physical activity, although another study found significant associations between functional limitation and the female gender ${ }^{19}$. However, it is worth noting that the setting of the present study was basic health units, meaning a selection bias can be assumed, with men more prone to previously installed adverse events.

The study by Paiva et al. ${ }^{22}$ found no significant association between the presence of morbidity and functional capacity in older adults, corroborating the findings of the present study. In the same context, the present study also agrees with the statements of the study by Paiva et al. ${ }^{22}$ that this finding may be justified by the fact that the older adults approached receive regular medical follow-up monitoring, and thus have their comorbidities controlled and do not therefore suffer functional impairment.

There was no association between physical activity and functional capacity. Moraes et al. ${ }^{23}$, in a study conducted in Fortaleza, did not find a direct relationship between these two variables. In contrast, the present study highlighted the relationship between reduced mobility and the absence of physical activity, regardless of sex, age and presence of comorbidities. The results of the study by Moraes et al. ${ }^{23}$ were similar, and the authors concluded that regular physical activity may be related to better functional mobility. Fernandes et al..$^{24}$ indicated in their results the importance of the practice of physical exercise for older adults and its positive impact on functional mobility. Thus, it can be stated that physical activity can act as a preventive health strategy, representing a protective factor for the loss of mobility, despite advancing age. ${ }^{25}$

In this context, primary health care should commit to providing comprehensive care for older adults and their families, as well as being at the forefront of the assessment of functional decline, seeking to develop promotion, prevention and rehabilitation strategies ${ }^{26}$; favoring health care with the aim of delaying the deleterious effects of the aging process, and preserving the independence and autonomy of older adults ${ }^{27}$. Primary care should therefore foster strategies that include care beyond medicalization and health care, with professionals and spaces that stimulate and favor the practice of physical activity and better physical performance in older adults, to prevent adverse events and stimulate healthy and active aging ${ }^{28}$.

However, given the importance of the theme, further studies with wider samples and cohort studies are suggested to allow a more accurate assessment of functional capacity and mobility in older adults, and which incorporate the training of primary care professionals, as part of the continuing education process and as a strategy to strengthen the scope of care offered to older users.

The main limitation of the present study was its sample, which is considered relatively small for an epidemiological study; and which was collected for convenience in only five of the 18 basic health units in the municipal region, due to the operational possibilities of the time and human resources available for the performance of data collection.

However, it is important to emphasize that this study was conducted with methodological rigor and the necessary care was taken in the sampling process, 
so that even if the sample was expanded, there would be little variation in the study parameters.

\section{CONCLUSION}

The present study found a significant association between functional capacity and age equal to or greater than 75 years; while the non-practicing of physical activity remained as a factor of association with reduced mobility, regardless of sex, age and the presence of comorbidities.
Based on these findings, the use of instruments for the assessment of functional capacity and mobility is of great importance for the development of specific actions aimed at the autonomy and independence of older adults, in view of the current population aging in Brazil. The results also emphasize the importance of practicing physical activity, the construction of spaces of health promotion and illness prevention to encourage active aging, and of a multi- and interprofessional approach to the integral health care of older adults.

Edited by: Ana Carolina Lima Cavaletti

\section{REFERENCES}

1. Sousa FD, Gonçalves LHT, Gamba MA. Capacidade funcional de idosos atendidos pelo programa saúde da família em Benevides, Brasil. Rev Cuidarte. 2018;9(2):2135-44.

2. Barreto MS, Carreira L, Marco SS. Envelhecimento populacional e doenças crônicas: Reflexões sobre os desafios para o Sistema de Saúde Pública. Rev Kairós. 2015;18(1):325-39.

3. Brasil. Ministério da Saúde. Portaria GM no 2.528 de 19 de outubro de 2006. Política Nacional de Saúde da Pessoa Idosa - PNSPI. Diário Oficial da União. 19 out 2006; Seção 1.

4. Kagawa CA, Corrente JE. Análise da capacidade funcional em idosos do município de Avaré-SP: fatores associados. Rev Bras Geriatr Gerontol. 2015;18(1):577-86.

5. Ferreira AP. Capacity and performance for the realization of basic activities of daily living (basic and instrumental) in elder dependents. Rev Baiana Saúde Pública. 2015;39(1):25-37.

6. Maciel ACC, Guerra RO. Limitação funcional e sobrevida em idosos de comunidade. Rev Assoc Med Bras. 2008;54(4):347-52.

7. Guralnik JM, Ferrucci L, Simonsick EM, Salive ME, Wallace RB. Lower-extremity function in persons over the age of 70 years as a predictor of subsequent disability. N Engl J Med. 1995;332(9):598-9.

8. Brasil. Ministério da Saúde. Portaria n ${ }^{\circ}$ 2.436, de 21 de setembro de 2017. Aprova a Política Nacional de Atenção Básica, estabelecendo a revisão de diretrizes para a organização da Atenção Básica, no âmbito do Sistema Único de Saúde (SUS). Diário Oficial da União. Set. 2017.
9. Costa EFA, Monego ET. Avaliação Geriátrica Ampla (AGA). Rev UFG. 2003;5(2):1-11.

10. Instituto Brasileiro de Geografia e Estatística.@ Cidades [Internet]. Rio de Janeiro: IBGE; 2018 [acesso em 27 ago. 2018]. Disponível em: https:// cidades.ibge.gov.br

11. Sousa AC, Dias RC, Maciel AC, Guerra RO. Frailty syndrome and associated factors in communitydwelling elderly in Northeast Brazil. Arch Gerontol Geriatr. 2012;54(2):95-101.

12. Lawnton MP, Brody EM. Assessment of older people: self-maintaining and instrumental activier of daily living. Gerontologist. 1969;9(3):179-86.

13. Shumway-Cook A, Brauer S, Woollacott MH. Predicting the probability for falls in communitydwelling older adults using the Timed Up \& Go Test. Phys Ther. 2000;80(9):896-903.

14. Fatori CO, Leite CF, de Souza LAPS, Patrizzi LJ. Dupla tarefa e mobilidade funcional de idosos ativos. Rev Bras Geriatr Gerontol. 2015;18(1):29-37.

15. Rolfson DB, Majumdar SR, Tsuyuki RT, Tahir A, Rookwood K. Validity and reliability of the Edmonton Frail Scale. Age Ageing. 2006;35(5):526-9.

16. Gavasso WC, Beltrame V. Capacidade funcional e morbidades referidas: uma análise comparativa em idosos. Rev Bras Geriatr Gerontol. 2017;20(3):399-409.

17. Almeida AV, Mafra SCT, da Silva EP, Kanso SA. Feminização da Velhice: em foco as características socioeconômicas, pessoais e familiares das idosas e o risco social. Textos Contextos. 2015;14(1):115-31. 
18. Berlezi ME, Farias AM, Dallazen F, Oliveira KR, Pillatt AP, Korte FC. Como está a capacidade funcional de idosos residentes em comunidades com taxa de envelhecimento populacional acelerado? Rev Bras Geriatr Gerontol. 2016;19(4):643-2.

19. Utida KAM, Budib MB, Batiston AP. Medo de cair associado a variáveis sociodemográficas, hábitos de vida e condições clínicas em idosos atendidos pela Estratégia de Saúde da Família em Campo GrandeMS. Rev Bras Geriatr Gerontol. 2016;19(3):441-52.

20. Marandi BAN, Silva BT, Abreu DPG. Avaliação da capacidade funcional de idosos: atividades das equipes da estratégia de saúde da família. Rev Pesqui Cuid Fundam. 2017;9(4):1087-93.

21. Campos ACV, Almeida MHM, Campos GV, Bogutchi TF. Prevalência de incapacidade funcional por gênero em idosos brasileiros: uma revisão sistemática com metanálise. Rev Bras Geriatr Gerontol. 2016;19(3):545-59.

22. Paiva SCL, Gomes CP, Almeira LG, Dutra RR, Aguiar NP, Lucinda LMF, et al. Influência das comorbidades, do uso de medicamentos e da institucionalização na capacidade funcional dos idosos. Rev Interdisciplin Estud Exp. 2014;6(n. único):46-53.
23. Moraes MPI, Sousa IAFC, Vasconcelos T. Relação entre a capacidade funcional e mobilidade com a prática de atividade física em idosos participantes de uma associação. Ciênc Saúde. 2016;9(2):90-5.

24. Fernandes AMBL, Ferreira JJA, Stolt LROG, Brito GEG, Clementino ACCR, Sousa NM. Efeitos da prática de exercício físico sobre o desempenho da marcha e da mobilidade funcional em idosos. Fisioter Mov. 2017;25(4):487-95.

25. Fidelis LT, Patrizzi LJ, Walsh IAP. Influência da prática de exercícios físicos sobre a flexibilidade, força muscular manual e mobilidade funcional em idosos. Rev Bras Geriatr Gerontol. 2013;16(1):109-16.

26. Roedl KJ, Wilson LS, Fine J. A systematic review and comparison of functional assessments of communitydwelling elderly patients. J Am Assoc Nurse Pract. 2016;28(3):160-9.

27. Polaro SHI, Gonçalves LHT, Alvarez AM. Building the gerontological performance of nurses in Family Health Programs. Rev Esc Enferm USP. 2013;47(1):160-7.

28. Aciole GG, Batista LH. Promoção da saúde e prevenção de incapacidades funcionais dos idosos na estratégia de saúde da família: a contribuição da fisioterapia. Saúde Debate. 2013;37:10-9. 